\title{
An Empirical Analysis of Emotions of Asian Indians During the First 100 Days of COVID-19
}

\author{
Siya Arora ${ }^{1}$, Vinish Kathuria ${ }^{2 *}$ \\ ${ }^{1}$ Student, The Shri Ram School - Aravali, Gurgaon, India \\ ${ }^{2}$ Research Scholar, Indian Institute of Management, Lucknow, India \\ *Corresponding author: efpm07014@iiml.ac.in
}

\begin{abstract}
India's COVID-19 tally was almost 8 million on September 26, 2020, while the global cases marched towards 42 million. People globally have been living under some sort of COVID-19-driven lockdown, stay at home, shelter-in-place, or some similar government-mandated measures. Living in a lockdown is NOT a natural phenomenon for most humans. How are people trying to manage themselves during the restrictions imposed on them? What are the mechanisms people are resorting to, to cope with this stress? Is their heritage, cultural or national differences that are allowing one segment to react better than the other? To address the research questions presented here, we leverage the qualitative analysis technique of narrative research to understand emotions and actions of 25 people of Indian heritage (spread across India, USA \& Canada) over the first 100 days of the COVID-19 pandemic and transpose the same with the Transactional Model of Stress and Coping. In this research, we present the initial findings from the ongoing study of global Indians and demonstrate that people are using a system of appraisal, response, and adaptation strategies. Both problemfocused and emotion-focused coping strategies are being leveraged, sometimes together. Reappraisal is driving a dynamic response to the evaluation and response process. Over 100 days, there is a shift from the physiological needs to the safety needs to love and belonging, and an overall shift from concern/panic to acceptance/co-existence. Practical, theoretical, and policy-related implications are discussed.
\end{abstract}

Keywords: COVID-19, Emotions, Indians.

\section{Introduction}

India's COVID-19 tally was almost 8 million on September 26, 2020, while the global cases marched towards 42 million. People globally have been living under some sort of COVID19-driven lockdown, stay at home, shelter-in-place, or some similar government-mandated measures. Living in a lockdown is NOT a natural phenomenon for most humans. The absence of social connections due to global lockdowns does not bode well for our emotional health and well-being. Added to this is the stress induced by COVID-19 at multiple levels, including the fear of a loved-one getting infected, living with others in confined spaces for long, as well as the anxiety of the uncertainty that lays ahead, whether professionally or from the societal attempts to co-exist with the COVID-19 virus.

The COVID-19 driven environment can be best described as an amalgamation of (a) concern for the immediate health of self and loved ones, (b) ensuring the availability of critical resources, (c) attempting to stay abreast with the latest hyperlocal, local, national and global developments, (d) emotional swings due to extended period of the lockdown and stay at home guidelines and (e) uncertainty of the future. How are people trying to manage themselves under the restrictions imposed on them? What are the mechanisms people are resorting to, to cope with this stress? Are there national and cultural differences that are allowing one segment to react better than the other?

The central tenet of the transactional model of stress and coping is that a potentially stressful event triggers the primary and secondary appraisal process people that allows them to assess the degree of threat concerning their wellbeing [1]. The primary appraisal process focused on the interpretation of the stress, while secondary appraisal process provides an assessment of the individual's coping resources and ability to manage the threat/challenge. Coping responses are initiated after the cognitive appraisals and reappraisal will include the feedback to the cognitive appraisal stages for further actions if required. In this research, we present the initial findings from the ongoing study and demonstrate that people are using a system of appraisal, response, and adaptation strategies. Our research shows the presence of both problem-focused and emotion-focused coping strategies, sometimes together. Reappraisal is driving a dynamic response to the evaluation and response process. Over 100 days, there is a shift from the physiological needs to the safety needs to love $\&$ belonging, and an overall shift from concern/panic to acceptance/co-existence.

The research complements other studies on general Indian public around knowledge, attitude, and anxiety [2] and depression, anxiety, and stress [3] which have used survey methodologies. A deeper analysis requires qualitative analysis techniques of narrative research and phenomenology, as used in this research. Narrative inquiry is an umbrella term that captures personal and human dimensions of experience over time and takes account of the relationship between individual experience and cultural context [4]. Phenomenology is the study of structures of consciousness as experienced from the first-person point of view [5]. A study of a particular cultural heritage (Indians in this case) spread across globe also is a key 
value addition of the research. This study has provided additional insights into the transactional process which will extend our understanding of how individuals appraise, cope, and experience stress in a pandemic.

\section{Literature Review}

\section{A. Stress}

Stress refers to a situation or event that requires consumers' mental and behavioral adjustments. When an environmental stimulus or event that could endanger well-being is perceived as exceeding a person's resources, psychological stress gets created [6]. Well-being is the experience of health, happiness, and prosperity experienced by an individual [7]. Stress affects peoples' lives and their mental and physical health [8]. The degree of stress experienced is directly proportional to what is at stake, higher the stake, higher would be the stress reaction [6].

A stressor is something that causes a state of strain or tension. It can be any event, experience, or environmental stimulus that causes stress in an individual. Researchers attribute stress stimuli to two types of physical or psychological events: major life events, and daily hassles [6]. The personal significance of the event would vary from person to person depending on their past, life stage, unique situation, and circumstances around the event. Unforeseen and unpredictable situations, like COVID19 , can typically cause a great deal of stress in a person's life.

\section{B. Emotions}

Emotions are an integral part of the human experience and are defined as a complex state of feeling that influence thought and behavior. As per Cognitive Appraisal Theory [9], emotions are extracted from our evaluations of events that cause specific reactions in different people. Thinking must occur first before experiencing emotion and our appraisal of a situation causes an emotional or affective response. Emotions involve a relational aspect, a motivational aspect, and a cognitive aspect [9].

\section{Coping}

Stress requires coping responses and ultimate behavioral outcomes depend on the types of coping strategies that consumers adopt [10]. When an individual's appraisal leads to a conclusion that the demands of an event exceed personal resources, coping mechanisms come into play. [1]. Coping strategies are aimed at eliminating, modifying, or avoiding encounters that give rise to problems [9]. Multiple coping strategies may be deployed to deal with elicited stress and failure consequences [11]. People cope with stress differently; some consumers may express their feelings; others may focus on action centric stress-reducing activities. Personality traits, and the nature of the stressful environment contribute to the coping mechanisms [12].

\section{Transactional Model of Stress and Coping}

In the Transactional Model of Stress and Coping [1], [6], [10] stress results from neither an environment nor a person alone.
Stress occurs because of the person-environment relationship that is appraised as taxing and endangering one's well-being. Individual judgement about the impact of the situation and ability to deal with it impact the level of stress. [1]. The model evaluates how major life events and daily hassles have an impact on emotions with the emphasis on cognitive appraisal and coping with stress.

The transactional model of stress and coping proposes that stress is experienced as an appraisal of the situation a person find himself/herself in [1] and that he/she goes through two stages of appraisal. In primary appraisal, the key evaluation is around the relevancy of the situation and probable gain or harm. (Figure 1), leading to an interpretation of the situation as positive, dangerous, or irrelevant. If dangerous, then secondary appraisal kicks in to decide if the individual can cope with the situation. This is done by an examination of the balance between situational demands (such as risk, uncertainty, difficulty) and perceived resources (amenities, social support, expertise). Negative stress in incurred where demands outweigh resources, and people engage in coping strategies.

To cope with the stress, people adopt either problem-focused or emotion-focused coping styles. Problem-focused approaches are generally action centric, where people try to change the situation into something more palatable. An emotion-focused approach, on the other hand, involves denial and avoidance, without a change in the nature of the problem itself. Some strategies that people follow include escape-avoidance, accepting responsibility or blame, exercising self- control, and engaging in positive reappraisals.

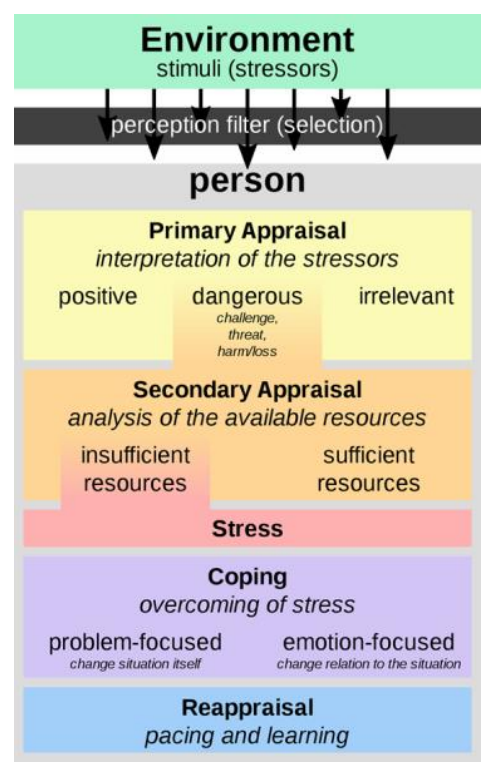

Fig. 1. The transactional model of stress and coping argues that our experience of stress is ultimately a system of appraisal, response, and adaptation (Lazarus \& Folkman, 1984)

Individual responses to stress and coping vary with time and situation. Indeed, as people try and cope, they make re- 
appraisals, once again going through the primary and secondary appraisal process. That is why the system is cyclical and transactional - appraisals drive individual responses, these responses changes something, and this change itself affects individuals' appraisals. The end results may be for an individual to stop being stressed or to change his/her coping style.

The transactional model of stress and coping has been extensively used and accepted in stress and health [13], organizational stress [14], chronic illness [15], critically ill [16], and HIV patients [17].

\section{Research Methodology}

\section{A. Narrative Research Approach}

To describe people's experience with the COVID-19 induced pandemic, we leverage the qualitative analysis techniques of narrative research and phenomenology. Narrative inquiry is the process of gathering information for the purpose of research through storytelling, through conversation around the relationship between individual experience and cultural context [4]. Phenomenology is the study of structures of consciousness as experienced from the first-person point of view [5], where the central structure of an experience is its intentionality.

People are natural storytellers, and stories are a means through which people generally communicate their life experiences. [18]. Narrative knowledge is created and constructed through stories of lived experiences to make sense of the ambiguity and complexity of human lives [19]. Narratives have been useful in research and have been conducted in the areas of HIV [20] and cancer [21].

\section{B. Participants}

Twenty-Five adults of Indian heritage from India (15) and North America (10) (US \& Canada) were involved in this study through convenience sampling. Lee \& Poole (2001) has used 15 samples whole researching the application of the Transactional Model to the Analysis of Chronic Illness respondents. In our study, there were 17 males and 8 females in the group. All, except one, were in the 40-60 years age group, while one participant was more than 60 years old. This age group was chosen since they are generally involved in caring for three generations - themselves, elders and children, and an attempt was made to collect their response to the collective group within the family and loved ones. Covid-19 cases, deaths, government responses and threat perception varied in the two regions during the period of the study. The respondents were college educated, English-speaking adults and open to sharing their experiences during COVID-19 lockdowns.

Researchers had one to one phone conversations with the participants in three different time frames. Since some global lockdowns/stay at homes started around mid- March 2020, we are using that period as Day 0 for our study and accordingly categorizing subsequent phases as Phase 1 - March 28-31, 2020 ( 2 weeks); Phase 2 - April 15-20, 2020 ( 4 weeks) and Phase 3 - June 18-24, 2020 ( 100 days). Participants were informed of the general purpose of the research. A generative narrative question was posed, and the resulting answers were left uninterrupted because the scientific integrity of the method depended on the interviewer being as unobtrusive as possible [22]. Post the uninterrupted narrative, follow-up questions allowed researchers to clarify doubts or ask additional probing questions, where needed. The combination of narrative data using a combination of holistic-content and categorical-content approaches [18] was used in this study because the holisticcontent approach allows for articulation of larger themes, common across participants and the categorical-content approach allowed us to report findings at a category level, ensuring the privacy of the participants.

\section{Analysis}

The narrative analysis yielded themes that we placed under five broad categories, as defined by the Transactional Model Primary Appraisal, Secondary Appraisal, Stress, Coping, and Reappraisal. We will present each category and its corresponding themes in succession, and many of the themes within these categories will contain quotes from participants' narratives described.

\section{Results and Discussion}

Analysis of the narratives shows a high level of awareness and focused actions related to their personal/ social/ professional lives across all respondents. The keyword analysis of conversation notes allows us to broadly classify the three phases as Concern, Reappraisal, and Uncertainty.

\section{A. Primary Appraisal}

The fast-paced changing environment commencing March 2020 - the lockdown, the empty roads, the closing of markets and commercial establishments, the new work norms, personal confinement to homes, global news, social media messages...all raised the anxiety levels and triggered certain insecurities. Danger dominated over positive and irrelevant sub-categories of the primary appraisal. Table 1 summarizes the transition of key concern areas for primary appraisal over 100 days.

\section{1) Fear for loved ones}

Across the board, people were very worried about the safety of their family \& loved ones. In Phase 1 (Concern phase), the fear of loved ones getting infected was mainly driven by the news around many infections in the USA, Italy \& China. Fear was higher in the minds of people who had family members away from home (a few had children studying outside the country) or elders (who are more vulnerable to the virus) living with them. As time passed, the anxiety levels went through peaks of highs and lows, depending on the personal and hyperlocal situation. For those, who knew of someone with the virus (or had lost a family member), the fear and anxiety levels went significantly high, almost to the state of panic. For others, the situation was more manageable. Almost all respondents mentioned that the, 
"stories around (virus) numbers going up and lack of beds (for patients) are not encouraging”.

The effect of getting infected with COVID-19 also led people to avoid visiting medical practitioners even for regular checkups and health issues.

"The fear is such that even for basic medical needs, we are now avoiding going to a doctor. My mother hasn't been to her doctor for three months now"

Over 100 days, as people saw others in their social circles getting impacted and then recovering, the sense of fear merged with a sense of relief. However, as global COVID-19 numbers crossed 10 million in June 2020, the fear factor again went high with concerns regarding the availability of appropriate health facilities in case of need.

2) Managing work/business, remotely

Work from home as a challenge and an opportunity came across in all conversations. This change, like any other, forced people to change their habits and routines, which became a challenge for most. The inherent belief that work cannot be done properly without physical interaction, was continuously hovering in everyone's minds. Finding personal spaces in respective homes for private online meetings or classes for children required adjustment for all. Three comments below best bring out the sentiments

"(It is) .... weird working from home, (because) everyone is here...."

"A lot of people collaborated to slowly achieve zero people working from office"

"They (the team) had never done work from home before so a lot of teething issues and now I feel they are fatigued"
As the months passed, people seem to appraise the idea of work from home differently. For some, it has now emerged as an efficient alternative to the usual in-office work, and some even believe it is the way to go after we get through this pandemic. However, for people in manufacturing, retail, hospitality, health, government, and similar sectors, work from home is not a long-term option and as countries have opened up in Phase 3, their primary appraisal is centered around ensuring safe commute, hygienic workplace, and workforce management.

\section{3) Transformation of social life as a cause of anxiety}

The first two phases were dominated by physiological and safety needs. However, as people got adjusted to the new normal, the growing need for love, belonging, and esteem started becoming important, in-line with Maslow's Hierarchy of Needs [23]. The cause for worry now tilted more towards the inability to physically interact with people outside the house. The loss of the sense of belonging and contentment that stemmed from these interactions occupied the minds of several individuals. Man is a social animal and being confined in small spaces for long is not natural for him. The urge to get out and interact with others formed a major part of Phase 3 conversations. The mass gatherings in the USA related to parties, political and cultural rallies brought out dual reactions -while there was overwhelming support for the causes, there was also a concern with an increased spread of the COVID19virus.

"(I) do not like how kids were partying during spring break, but overall support the measures being taken"

\section{4) Response to Government Initiatives}

The appraisal of government actions in the face of the pandemic varied across the countries of the world. In phases 1 and 2, the respondents from India seemed to have a favorable attitude towards the steps taken by their government, although Table 1

Transition of key concern areas for Primary Appraisal over 100 days

\begin{tabular}{|c|c|c|c|}
\hline Primary Appraisal & Phase 1 ( 2 weeks) & Phase 2 ( 4 weeks) & Phase 3 ( 100 days) \\
\hline & Concern & Reappraisal & Uncertainty \\
\hline Dislikes & $\begin{array}{l}\text { - Confinement to homes } \\
\text { - Shut down of shops, malls, } \\
\text { cinemas } \\
\text { - No help for household work }\end{array}$ & $\begin{array}{l}\text { Wearing masks and using sanitizers } \\
\text { very often } \\
\text { - No food from restaurants or fast-food } \\
\text { joints }\end{array}$ & $\begin{array}{l}\text { - Uncertainty due to ever-increasing cases } \\
\text { - Lack of recreation options } \\
\text { - Not going out for summer vacation }\end{array}$ \\
\hline $\begin{array}{l}\text { Getting used to / } \\
\text { learnings }\end{array}$ & $\begin{array}{l}\text { - Staying at home and keeping } \\
\text { busy } \\
\text { - Hygiene and protective } \\
\text { measures } \\
\text { - Doing household work }\end{array}$ & $\begin{array}{l}\text { - Learning and using remote working } \\
\text { tools } \\
\text { - Co-existing with family members } \\
\text { while working } \\
\text { - Socializing digitally } \\
\text { - Using Masks \& Sanitizers }\end{array}$ & 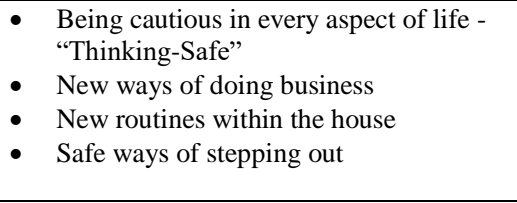 \\
\hline
\end{tabular}


some hoped for better execution. The strict measures taken were considered the need of the hour by most. As the months passed, these respondents now felt an increasing need for the restrictions to be eased but also expected the government to do so in a manner that does not lead to a spurt in the number of cases. Respondents from the USA however, seemed discontented with the policies of the federal government and did not feel the situation was being taken as seriously as it should. Respondents from the UK and Canada, while being appreciative and supportive of government actions, preferred stricter controls than what they were seeing. Phase 3 conversations show that most understood the limitations of being dependent only on the government and hence have decided to rely more on self-awareness, self- imposed restrictions, and hyperlocal neighborhood initiatives.

\section{5) Uncertainty of the future}

One of the key questions in most people's minds was "how long will this continue?" The sheer lack of knowledge about when this situation would come to an end translated into several insecurities - work, the wellbeing of their families, and the future of their lives in general. Through the course of the study, as the end of this pandemic becomes more and more unclear, this uncertainty has gone up.

\section{B. Secondary Appraisal}

Analysis of the type of resources people had to deal with the above-mentioned fears and insecurities was also something that the people engaged in. Their appraisal of whether these resources were sufficient varied across categories and time. Table 2 summarizes the transition of key concern areas for Secondary Appraisal over 100 days.

1) Groceries and food supply

In the earlier stages of the study, most people in India felt that they had a good enough stock of food and other groceries for themselves and their families. Even though they realized that eventual shortages were inevitable, the supply chain of groceries and food seemed to be in place now. Home delivery also provided support to families in circumstances that did not permit going out to purchase these necessities. However, long lines and stock hoarding was reported in parts of the USA.

"When the first case was reported in (his) area, there was a high amount of panic among people. People tried to buy (things) ... knowing some issues will happen in the supply chain”

"The line at Costco (grocery and warehouse store) is 200 people long. Looks like I will be here for 2 hours"

Over the 100 days duration, things seem to have settled down. The later stages of the study showed that this supply chain has rationalized, with some early problems also no longer being causes of concern.

\section{2) Health and Sanitary requirements}

A shortage of sanitizers and toilet paper became almost characteristic of the USA and Canada around the time of our first round of interviews. This left people worried and struggling to find a way to procure enough of these resources. As time passed, the issues related to toilet paper have gone away, indicative of an improvement in the supply chain. India did not see a shortage of these products throughout this study (except for difficulty in procuring sanitizers faced by a few people). This was also a result of the low consumption of toilet paper in Indian households regularly. The shortage of masks was overcome by people using homemade masks for everyday use. Though concerns with adequate PPE (Personal Protective Equipment) availability for health professionals continue to make the news, none of the respondents was in the health sector and hence had not experienced the same.

\section{3) Digital Alternatives}

Initially, most respondents were skeptical of how the digital world could ever serve as a sufficient replacement for the real world. Be it for work, education, or social interaction, people were worried that digital alternatives to the real world would not help them achieve their usual productivity (in case of work and education) and the same level of human connection (in case of social interaction). The later rounds of the study, however, revealed that people had now begun to consider the online space as their new "real" world, and had found ways to make use of the digital resources in a manner that met, and sometimes even surpassed their needs.

\section{4) Ways to keep occupied}

Another common feeling that emerged since Phase 2 of the study was the sudden lack of ways to keep oneself occupied. Older adults and senior citizens were confined to their respective homes and continued to struggle with keeping themselves meaningfully engaged. Closure of religious places and places of the congregation also added to the situation. This

Table 2

Transition of key availability of resources during Secondary Appraisal

\begin{tabular}{|c|c|c|c|}
\hline Secondary Appraisal & Phase 1 ( 2 weeks) & Phase 2 ( 4 weeks) & Phase 3 ( 100 days) \\
\hline Insufficient Resources & $\begin{array}{l}\text { - Availability of groceries } \\
\text { - Availability of medicines } \\
\text { - Access to medical centers \& doctors }\end{array}$ & $\begin{array}{l}\text { - Availability of masks \& sanitizers } \\
\text { - Access to medical centers \& } \\
\text { doctors } \\
\text { - Food from restaurants or fast-food } \\
\text { joints }\end{array}$ & $\begin{array}{l}\text { - Access to medical centers \& doctors } \\
\text { - Knowledge regarding the length of } \\
\text { lockdowns } \\
\text { - Future of business \& jobs }\end{array}$ \\
\hline
\end{tabular}


was also a concern for the youth, for whom the time spent in school/ college as well as their social interactions earlier took up a large part of their days. This, in turn, also made parents feel that they did not have enough activities (resources) to keep their children busy.

"My daughter is a social person and is struggling with being at home."

"It has been a challenge to keep the kids busy and engaged. While the older daughter is busy in her schoolwork, the younger one is getting restless"

\section{"I feel helpless and sad."}

\section{5) The Vaccine}

The absence of a vaccine is an ongoing concern. From past experiences of H1N1, SARS, and other outbreaks, people expect a vaccine to be the answer to COVID-19.

\section{Stress}

According to the Transactional Model, primary appraisal of a situation as dangerous and a secondary appraisal of having insufficient resources to cope typically leads to stress. Throughout this study, different factors (stressors) led to a feeling of stress among individuals.

\section{1) The danger of the virus}

The COVID-19 virus disease is, naturally, a threat to human health. Respondents' appraisal of this newfound virus as dangerous coupled with the understanding that as of now, there is no way to prevent or cure it completely (insufficient resources) caused anxiety, worry, and stress. In the initial stage of the study, stress regarding catching the virus was at an alltime high. Nobody was sure how easily one could get infected, neither did they know if their actions were safe or unsafe. Since most people did not personally know people who were infected, their understanding of what the disease entails was also limited.

\section{"My wife has not stepped out of the apartment for the last 6 weeks"}

"No one in the neighborhood is stepping out."

As time progressed, restrictions became less, knowledge about COVID-19virus grew, and news about recovery also started making the rounds, some stress levels decreased. However, considering the hyperlocal impact of COVID19virus and the ongoing uncertainty about medical resources, stress levels related to the virus are still high in Phase 3.

\section{2) Essential resources}

As mentioned above, the availability of essential resources stopped being a stress item for most by Phase 2 .

3) Preventive measures and healthcare

Besides staying inside the house, the only known way to reduce the chances of contracting the virus was by wearing protective gear (masks and gloves) and sanitizing. As a result of the sudden increase in the demand for these protective goods, people faced challenges in getting the supply they needed (insufficient resources), which invariably led to stress. Another cause of worry was the fact that, with the growing number of cases and the perceived unsafe environment of hospitals, healthcare for people, especially elders, suffering from other health problems might be compromised. In phase 3, there are ongoing reports around inadequate testing and medical resources and patients being forced to run from pillar to post to get adequate care, adding to stress levels.

4) Financial concerns and job security

According to IMF, the global economy is expected to shrink by $4.9 \%$ in 2020 , the steepest slowdown since the Great Depression of the 1930s [22]. In the USA, more than 45 million people have filed initial unemployment claims as businesses have closed their doors and consumers have gone into lockdown (Ruscha, 2020). After individuals had all the essentials in place, they began to feel stressed about the future of their jobs and businesses. The fact that the pandemic brought several sectors of the economy to a standstill is indeed a cause for concern. Layoffs have started to occur. Professional and financial uncertainty is only increasing stress.

\section{5) Emotional stress}

In public mental health terms, the main psychological impact to date is the elevated rates of stress or anxiety. Levels of loneliness and depression are forcing people to think more about satisfying their emotional needs of companionship, love, and social interaction. With the lockdown restricting physical human interaction almost completely, this fulfilment poses a challenge and consequently, becomes stressful. People continue to dislike the confinement, the restriction, and being unable to socialize.

\section{Coping Mechanisms}

Respondents' efforts fit perfectly into the two types of coping - Problem-focused coping and Emotion-focused coping. It was observed that as time passed, there was a shift in the kinds of factors causing stress to individuals. This led to more efforts being made to cope with emotions and less to cope with the problem itself. Table 3 shows the different types of coping mechanisms with some examples.

\section{1) Problem-focused coping}

The factors causing stress to individuals can be grouped into the following categories: the virus itself, procuring essential resources, and economic insecurities. People used different action-driven mechanisms to cope with these stressors. Social distancing. - All respondents reported adherence to social distancing norms imposed by the government, although the degree varied. Sanitizing, handwashing, and masks - As individuals felt it necessary to step out of the house, they were careful to wear masks, and sometimes gloves. In some families, home deliveries were being given 'breathing room' outside the home and sanitization was being done before they were brought 
Table 3

Types of coping mechanisms

\begin{tabular}{|l|l|l|}
\hline Coping with stressors & \multicolumn{1}{|c|}{ Coping mechanisms } & \multicolumn{1}{c|}{ What people said } \\
\hline Problem-focused coping & $\begin{array}{l}\text { - Social distancing } \\
\text { - Sanitizing, handwashing, and masks } \\
\text { - Staying informed } \\
\text { - Stocking up essentials }\end{array}$ & $\begin{array}{l}\text { "My wife and family are not stepping out of the house even though some people } \\
\text { in the neighborhood can be seen walking outside." } \\
\text { "We are following all social distancing norms" }\end{array}$ \\
\hline Emotion-focused coping & $\begin{array}{l}\text { - Family bonding } \\
\text { - Social support } \\
\text { - Physical fitness and Spirituality } \\
\text { - Keeping occupied } \\
\text { - Cognitive coping }\end{array}$ & $\begin{array}{l}\text { "There is a good conversation happening between all four family members." } \\
\text { "I australia, UK, or other parts of the world. I am grateful for the opportunity to talk } \\
\text { to my friends in these times" } \\
\text { "It feels good to know that everyone is in the same boat." }\end{array}$ \\
\hline
\end{tabular}

into the house. Families also made it a point to wash their hands regularly. However, Phase 3 narratives have revealed that (a) mask adherence is not present in USA, (b) people have slowly reduced the strictness of social distancing due to both fatigue and less adherence by people around them, (c) Sanitization practices continue.

Other actions related to problem-focused coping included:

- Staying informed: An important way that individuals were trying to make sure they do not catch the virus was by staying informed about things like the nature of the virus, how it spreads, how long it lives on different surfaces, its incubation period, etc. News and social media continue to be the dominant source of information to individuals through all phases.

- $\quad$ Stocking up: Across countries, people either ensured that they had enough stock of essential items to sustain them for a while or began to stock up large amounts of food products, medicines, toilet paper, sanitizers, etc. As the lockdown continued, people began to observe that the supply chain was still intact and that the lockdown situation was here to stay. This made people realize that stocking up was not the most practical option and led them to buy goods in quantities to sustain them for shorter periods.

2) Emotion-focused coping

Over time, as people's basic needs of survival, health and safety were being fulfilled, emotional factors such as loneliness, insecurity, uncertainty, unproductivity, sadness, etc. became more common as causes of stress. This led to an increased emphasis on emotion-focused coping.

- Family bonding: Many people found spending time with their family members to be a useful coping mechanism. Although initially, with everyone at home, time spent with the family was almost by default. However, over time, the realization that the entire family was in this together for the long haul made individuals consciously take up activities like playing board games and routines like having meals together, or simply talking to each other more.

"There is a good conversation happening between all four family members."
"My husband and son are home now, and the family is together after a long time. We are trying to have our meals together. This makes us happy"

"We as a family are spending good time with parents and kids. Trying to stay happy following a $100 \%$ lockdown within our home."

Parents and children, usually busy with work and school, now had the time and the inclination to spend more time with the elders of the house. Family members became important pillars of support against the feelings of loneliness and frustration that the pandemic, and in particular social distancing, brought. Also, the fact that one's family members are around and safe brought a lot of comfort. Social Support People made conscious efforts to connect digitally, by organizing group video calls, connecting with old friends, spending more time on social media, etc.

"I am constantly chatting with my global friends, whether they are India, Australia, UK, or other parts of the world. I am grateful for the opportunity to talk to my friends in these times."

In many countries like India, UK, Italy, and Spain, the beginning of the lockdown was marked with a surge in community spirit, wherein thousands of people were seen stepping out of their houses at the designated time and clapping and appreciating the efforts of the health practitioners. These activities also acted as social bonding tools and boosted morale.

- Physical fitness and Spirituality: A few weeks into the lockdown, individuals realized that they would be confined to their homes for a long time. This meant a loss of physical activity, be it going to the gymnasium or simply walking to the market. Several individuals were found to emphasize keeping their body healthy. Exercise, as is well known, is an extremely effective stressbuster. People adopted at-home workouts, yoga, and walks within the residential complex to keep themselves healthy. Some respondents also revealed that they were trying to get in touch with their spiritual side, through things like meditation, prayers, and listening to religious melodies, to ease their tension \& worries and stay calm. 
"Prayers, Conversations, Making Meals, Watching Movies, Playing together"

- Keeping occupied: Although in the early phase of the lockdown, getting all the basics in place took up most of the people's time, after a point, individuals began to find it difficult to keep themselves occupied. Many said that office/ schoolwork as well as doing the house chores did keep them busy for the most part, but it became important to find alternative ways of recreation. In addition to the obvious use of technology (watching movies and videos, using social media, online games, etc.), people now came up with new activities that could easily be done at home. These ranged from playing sports on the roof or balcony, taking up online courses, volunteering to just sitting outside, and appreciating nature. Focus on positivity came across clearly when respondents were asked about advice to others in the same situation.

"Be positive, tomorrow will be a better day, for now, enjoy family time"

"Stay positive, do more of what you are good at. Be extra mindful to help others in whatever way you can"

- Social Comparison: Also, news regarding the plight of those less fortunate made people feel thankful for the privileges they had, during these unforeseen circumstances. The very fact that they had the facilities to connect with friends or the resources (money, food, shelter) that others may not have played a very important role in replacing the question of "why me?" with a feeling of gratitude.

\section{E. Reappraisal}

Reappraisal is defined as an altered appraisal of new input from one's environment and an assessment of something or someone again or differently. Reappraisals to the dynamic environment created by COVID-19 induced lockdowns, leading to pacing and learning, are visible in most of the conversations. In line with Maslow's Hierarchy of Needs [24], we see a shift from physiological and safety needs in Phase I to Love \& Belonging and Esteem in Phase III. In the early days, the most focus was on staying healthy and ensuring a supply of daily needs and essential goods (groceries, medicines). By Phase 2, most respondents had gotten used to the new way of living in a lockdown - work from home, restrictions on travel, access to essential items, etc. However, some respondents had to experience extensive containment for a few days and the reappraisal of essential item availability became a daily routine. While a Lockdown is a general state of isolation or restricted access instituted as a security measure, a Containment zone is an extreme form of the same where extra restrictions on the movement of people, goods, and services get put in place for a specific area.

"(We) went inside a 'containment zone' 3 days ago, so learning the new way of living in a lockdown".

By the 100-day mark of Phase III, all respondents were missing their friends, colleagues, relatives, and one could see the concepts of Love and Belonging driving their thoughts. Some had started going to the office to maintain a sense of selfesteem and status and get a sense of freedom and external recognition for their actions. This was most visible with senior industry professionals who were missing their identity and finding it suffocating to continue working inside the premises of their homes. As identified in the Transactional Model, the process of primary \& secondary appraisals and coping starts again after a reappraisal. A few new items related to travel, daily commute, intrastate border closures, and maintaining social distancing in the workplace get added to the evaluation process in Phase III. and challenges in the field.

\section{Conclusion}

In this research, we present the initial findings from the ongoing research that aims at understanding an individual's journey from stress to well-being in the context of the onset of the COVID-19 pandemic. Keeping in mind the prevailing situation and people's general discomfort with sharing emotions and feelings, we leveraged the narrative analysis methodology. It allowed us to examine how the different components of a person's context (e.g. morals, values, beliefs) interact with one another to construct a more holistic view of the person's life, his/her analysis of the COVID-19 situation and appropriate coping mechanisms. We believe and have been able to demonstrate that knowledge increases through telling stories because narratives allow a respondent to dig deeper and explain their actions. Transposing the narrative approach with the Transactional Model allowed us an effective framework to reflect on how people are feeling and why. In a dynamic situation like COVID-19 with concerns around health, resource availability, and future uncertainty, our findings demonstrate that people are repeatedly (re) evaluating primary and secondary appraisals and identifying the resource and demand balance. The coping strategies are also dynamic, with a shift from problem-focused to emotion-focused and vice versa. Our analysis shows that sometimes, taking a step back from things gives one a chance to cope more creatively, and in a more adaptive way. However, happiness matters, and willingness to overcome obstacles has been a testament of humans for ages. It is the same will and desire to march towards well-being that the study demonstrates. The respondents' shift from the physiological needs to the safety needs to love \& belonging has significant managerial and policy implications as companies and governments make efforts to reopen. Compassion and Empathy are the need of the hour and should be reflected in all 
decisions and actions taken by the decision-makers. An overall shift from concern/panic to acceptance/co-existence and a positive attitude bodes well for the upcoming phase of trying to get to a new "normal" way of life.

\section{Declarations}

\section{Study Limitations:}

There are a few noticeable limitations with the study, primarily being the limitations with the qualitative research and narrative analysis technique approach, which depends on the effective relationship between the researcher and the participants; the participants' concern about the privacy, authorship, ownership; and the voice of both the participant and the researcher. While we have made our best efforts to reduce our own bias and represent the voice of the respondents, being a part of the COVID-19 impacted ecosystem, our beliefs and experiences may have permeated into the analysis. The sample size of 25 does not represent the human population and extrapolation of the learnings to all geographical population segments should be done with caution.

\section{References}

[1] R. S. Lazarus. and Folkman, S. (1987). "Transactional theory and research on emotions and coping”, European Journal of Personality. 1, 141-169.

[2] D. Roy, Sarvodaya Tripathy, Sujita Kumar Kar, Nivedita Sharma, Sudhir Kumar Verma, Vikas Kaushal (2020), "Study of knowledge, attitude, anxiety \& perceived mental healthcare need in Indian population during COVID-19 pandemic", Asian Journal of Psychiatry, Volume 51.

[3] S. Verma, Mishra A (2020), "Depression, anxiety, and stress and sociodemographic correlates among general Indian public during COVID-19". International Journal of Social Psychiatry. 2020;66(8):756-762.

[4] D Jean Clandinin, \& Connelly, F. Michael. (2000). Narrative Inquiry: Experience and Story in Qualitative Research.

[5] S. Gallagher (2012). "What Is Phenomenology?" in Phenomenology. Palgrave Philosophy Today. Palgrave Macmillan, London.

[6] R.S. Lazarus and Folkman, S. (1984). Stress, appraisal, and coping. New York, NY: Springer Publishing Company.

[7] Naci Huseyin, John P. A. Ioannidis (2015). "Evaluation of Wellness Determinants and Interventions by Citizen Scientists". Journal of American Medical Association. 314 (2).

[8] S.E. Hobfòll (1989). "Conservation of resources: A new attempt at conceptualizing stress". American Psychologist. 44, 513-524.
[9] Richard S. Lazarus (1991). "Progress on a cognitive-motivationalrelational theory of Emotion" American Psychologist. 46(8), 819-834.

[10] S. Folkman, Lazarus, R.S., Gruen, R.J., and DeLongis, A. (1986), "Appraisal, coping, health status, and psychological symptoms". Journal of Personality and Social Psychology. 50, 571-579.

[11] A. Duhachek, (2005). "Coping: A multidimensional, hierarchical framework of responses to stressful consumption episodes". Journal of Consumer Research. 32, 41-53.

[12] Charles S. Carver and Michael, F. Scheier. (1994). "Situational Coping and Coping Dispositions in a Stressful Transaction". Journal of Personality and Social Psychology, 66 (1), 184-95

[13] L. Yu, Chiu, C.-H., Lin, Y.-S., Wang, H.-H., \& Chen, J.-W. (2007). "Testing a model of stress and health using meta-analytic path analysis". Journal of Nursing Research. 15(3), 202-214.

[14] C.L. Cooper, Dewe, P.J., and O’Driscoll, M.P. (2001). Organizational Stress: A review and critique of theory, research, and application (pp. 159-183, pp. 233-252). Thousand Oaks: Sage Publication, Inc.

[15] Andrea Lee and Poole, Gary. (2005). "An Application of the Transactional Model to the Analysis of Chronic Illness Narratives". Qualitative health research. 15, 346-64.

[16] J. F. Byers and Smyth K. A. (1997). "Application of a transactional model of stress and coping with critically ill patients." Dimensions of Critical Care Nursing. DCCN Nov-Dec. 16(6), 292-300

[17] L. J. Graham (2015). "Integration of the Interaction Model of Client Health Behavior and Transactional Model of Stress and Coping as a Tool for Understanding Retention in HIV Care Across the Lifespan." Journal of the Association of Nurses in AIDS Care. Volume 26, Issue 2, Pages 100-109,

[18] A. Lieblich, Tuval-Mashiach, R., and Zilber, T. (1998). Narrative research: Reading, analysis, and interpretation. Thousand Oaks, CA: Sage.

[19] J. Bruner. (1986). Actual minds, possible worlds. Cambridge, MA: Harvard University Press.

[20] D. Ezzy (2000). "Illness narratives: Time, hope, and HIV". Social Science \& Medicine. 50, 605-617.

[21] C.S. Lee (2001). "The use of narrative in understanding how cancer affects development: The stories of one cancer survivor". Journal of Health Psychology. 6(3), 283-293.

[22] J. Horowitz (2020), "The recession is much worse than the IMF expected and the hit to jobs 'catastrophic'. CNN.

Available at https://edition.cnn.com/2020/06/24/economy/imf-economicoutlook/index.html. (Accessed June 28, 2020)

[23] Rushe D. (2020), "US unemployment claims rise by 1.5 million as pandemic pain continues", The Guardian.

Available at:

https://www.theguardian.com/business/2020/jun/18/us-unemploymentclaims-rise-coronavirus-economy-latest (Accessed June 28, 2020)

[24] Maslow, A. H. (1943)." A theory of human motivation", Psychological Review, 50(4), 370-396. 